\title{
Market differentiation threshold and the relationship between corporate social responsibility and corporate financial performance
}

\begin{abstract}
This study assesses the impact of corporate social responsibility (CSR) on corporate financial performance (CFP) by using an innovative threshold estimation technique. We examine whether the CSR effect on CFP is varied with the distinct levels of market differentiation. The empirical analysis is based on a world automotive panel dataset for the period of 2011-2017. We unveil an inverted V-shaped relationship between CSR and CFP and confirm that the increasing nonparametric regression line up to a certain threshold level indicates a positive effect on CFP, whereas a decreasing line indicates a negative effect. Hence, these findings support the idea that engagement in CSR can boost firm performance by incorporating with market differentiation, since higher firm performance is associated with strong differentiation (i.e., less substitutability), but CSR may not provide large benefits in firms with too high market differentiation.
\end{abstract}

Keyword: Corporate financial performance; Corporate social responsibility; Market differentiation, threshold regression 